\title{
Redesigning China's superblock neighbourhoods: policies, opportunities and challenges
}

\section{Citation}

Kan, Har Ye, Ann Forsyth, and Peter Rowe. 2017. “Redesigning China's Superblock

Neighbourhoods: Policies, Opportunities and Challenges." Journal of Urban Design 22 (6) (June 27): 757-777. doi:10.1080/13574809.2017.1337493.

\section{Published Version}

10.1080/13574809.2017.1337493

\section{Permanent link}

http://nrs.harvard.edu/urn-3:HUL.InstRepos:37093807

\section{Terms of Use}

This article was downloaded from Harvard University's DASH repository, and is made available under the terms and conditions applicable to Open Access Policy Articles, as set forth at http:// nrs.harvard.edu/urn-3:HUL.InstRepos:dash.current.terms-of-use\#OAP

\section{Share Your Story}

The Harvard community has made this article openly available.

Please share how this access benefits you. Submit a story.

\section{Accessibility}




\title{
Redesigning China's Superblock Neighborhoods: Policies, Opportunities, and Challenges
}

\author{
Har Ye Kan, Ann Forsyth, Peter Rowe \\ Journal of Urban Design
}

May 2017 version

\begin{abstract}
In February 2016, China's State Council released guidelines representing a change in the country's approach toward neighborhood design: to move away from superblock neighborhoods and create a finer network of urban blocks and streets. The paper traces the circumstances that prompted this change. Drawing on a comparative review of international literature and practice, it explores the opportunities and challenges for urban design. While modifications of the superblock are somewhat overdue, it should not be entirely abandoned. The suggestions and overall blueprint warrant a more circumspect approach and should be adopted with discretion.
\end{abstract}

Keywords: Superblock neighborhoods, Gated communities, China 


\section{Introduction}

A defining feature of Chinese cities is the prevalence of the bounded superblock neighborhood. Bounded typically by wide arterial roads, these neighborhoods occupy sizeable blocks measuring between 300 and 500 meters in length and width, cordoned off by a mixture of walls, fences, plantings, gates, and guard houses, affording different degrees of public access. Within each of the 12- to 20-hectare tracts are clusters of single- or multi-family housing supported by small-scale retail services and community facilities. These clusters typically accommodate some 150 to 3,600 dwelling units in total, or up to 10,800 residents at a household size of around 3 persons (Wang 2015; Li 2013; Miao 2003). Usually containing mid- to high-rise slabs and towers set in landscaped environs, developments yield high residential densities on the order of about 200 to even 900 people or more per hectare (Rowe et al 2016).

This combination of bounded superblock neighborhoods and a coarse-grained street network has characterized much of modern Chinese planning since 1949, and particularly after the 1978 economic reforms. However, it is potentially poised for an overhaul. On February 6, 2016, the Chinese State Council issued guidelines, entitled "The Central Government of the Communist Party - Several Guidelines by the State Council on Promoting and Reinforcing Planning Construction and Management." Among the long list of 27 areas in which specific suggestions were made are calls "to cease the construction of enclosed residential neighborhoods, in principle [emphasis added]," and "to create a dense urban road network with narrower streets" (Ministry of Housing and Urban-Rural Development of the People's Republic of China 2016).

The article explores the implications of these guidelines. It first analyzes the origins and distinctiveness of the superblock neighborhood in China and elsewhere, unpacking two key ideas underpinning the urban strategy: (i) the physical neighborhood and its tradition, and (ii) the superblock and its genealogies. The paper then elaborates on the new planning and urban design directives released by the Chinese State Council, examining their implementation opportunities and challenges. It shows that there are exceptional overlaps between bounded superblocks as physical neighborhoods and local units of community governance in China. While opening up of the blocks will not necessarily change the governance, increased physical access from outside will provide new challenges for managing public space. There are also more and less heavyhanded approaches to opening up existing superblocks with implications for physical connectivity and community disruption.

How important the directives will be for Chinese urban development and redevelopment is a topic of some debate. The directives were issued after the high-level Central Urban Work Conference was held in Beijing in December 2015 and represent the blueprint for urban planning and development between 2016 and 2020. More importantly, because this was the second time the conference was held in 37 years, both the conference and its resultant directives have been perceived in some quarters as a milestone in charting urbanization for a "New China" (Xinhua News 2016). It is unclear how committed the ministry is to these suggestions, how much weight to give to the superblock components among numerous other elements, and the specific role of the Ministry of Urban-Rural Development in relation to others like the National Development and Reform Commission (dealing in part with planning practices) and the Ministry of Land. 
With a mix of fairly detailed national policies and some suggestions about local solutions to local problems, the guidelines themselves reflect some of this complexity. However, no matter how powerful the guidelines turn out to be, the problems and potentials of Chinese superblocks remain important concerns.

\section{Bounded Superblocks and Neighborhoods: Origins \& Comparisons Physical and Social Dimensions}

The idea of being able to build a neighborhood - a residential district with an identifiable core or boundary, that also has a social reality - has been a recurring one in urban planning in the past century or more (Brower 1996; Ward 2002). Several key approaches have had wide international use. Some are based on the physical superblock or megaplot, a structure separating pedestrians from fast-moving vehicles and providing a protected area, in this case residential. While a largely physical structure, the superblock has been seen as a way to bring people together on shared paths and open spaces; it has also been overlaid with additional services (Brower 1996). One way of structuring services, important in China as well as many other places abroad, has been the neighborhood unit, or the xiaoqu, typically centered around a school and other community facilities ( $\mathrm{Li} 2013$ ). Finally, neighborhood-level community governance structures have been either integrated into the wider government, representing a form of shadow government such as a home-owner association, or become the product of social activism (Silver 1985; Li 2013). As such, while the physical superblock, the physical-social neighborhood unit, and neighborhood governance are distinct entities, these can overlap in practice. While some of these neighborhood governance structures may be integrated into planning processes, many are not.

In China, the superblock has often defined the physical dimensions of neighborhoods. According to Whiting (2004), there are three major paradigms underpinning the superblock strategy: (i) park-like configurations from the Garden City movement at the turn of the twentieth century; (ii) the parallel and perimeter block layouts by Dutch, Austrian, and Russian architects from the early twentieth century; and (iii) the Modernist high-rise towers or slabs in a park within a grid. Each of these international paradigms shaped housing forms in China but in each case, there was a lapse of several decades before these ideas actually took root (see Figure 1). The most influential of these were the perimeter and parallel neighborhoods that defined much of planning and architectural practice since the 1950s (Lü et al 2001; Rowe et al 2016). A national debate on the strengths and weaknesses of the perimeter and parallel designs ultimately ruled in favor of the latter throughout much of the 1960s and 1970s (Lü et al 2001). More contemporary residential estates from the 1980s onwards were constructed in the vein of Modernist superscaled plats. These were developed at a range of densities and coverages. Superblocks also varied: from traffic calmed to traffic free, from completely walled, gated, and guarded developments on parking podiums to relatively porous boundaries that mainly slow through traffic (Rowe et al 2016).

Several factors generated the bounded nature of existing Chinese superblocks. Before the 1980s, enclosed danwei or work unit compounds and estates defined the residential arrangements in communist China. With the commodification of housing, early experiments in the design of residential neighborhoods between 1986 and 1990 were organized in the form of housing clusters surrounding central green spaces and recreational facilities. Although the then Ministry 
of Construction did not mandate the construction of enclosed neighborhoods, the development model stipulated that property developers were responsible for providing the necessary amenities in the project itself. This helped to reduce the amount of public investment to be undertaken by the Ministry but it meant that the costs of the public facilities were borne collectively by the property owners, prompting developers to exclude outsiders from using these facilities (Xiu 2016).

\section{Figure 1: Superblock/Megaplot Intellectual Sources}
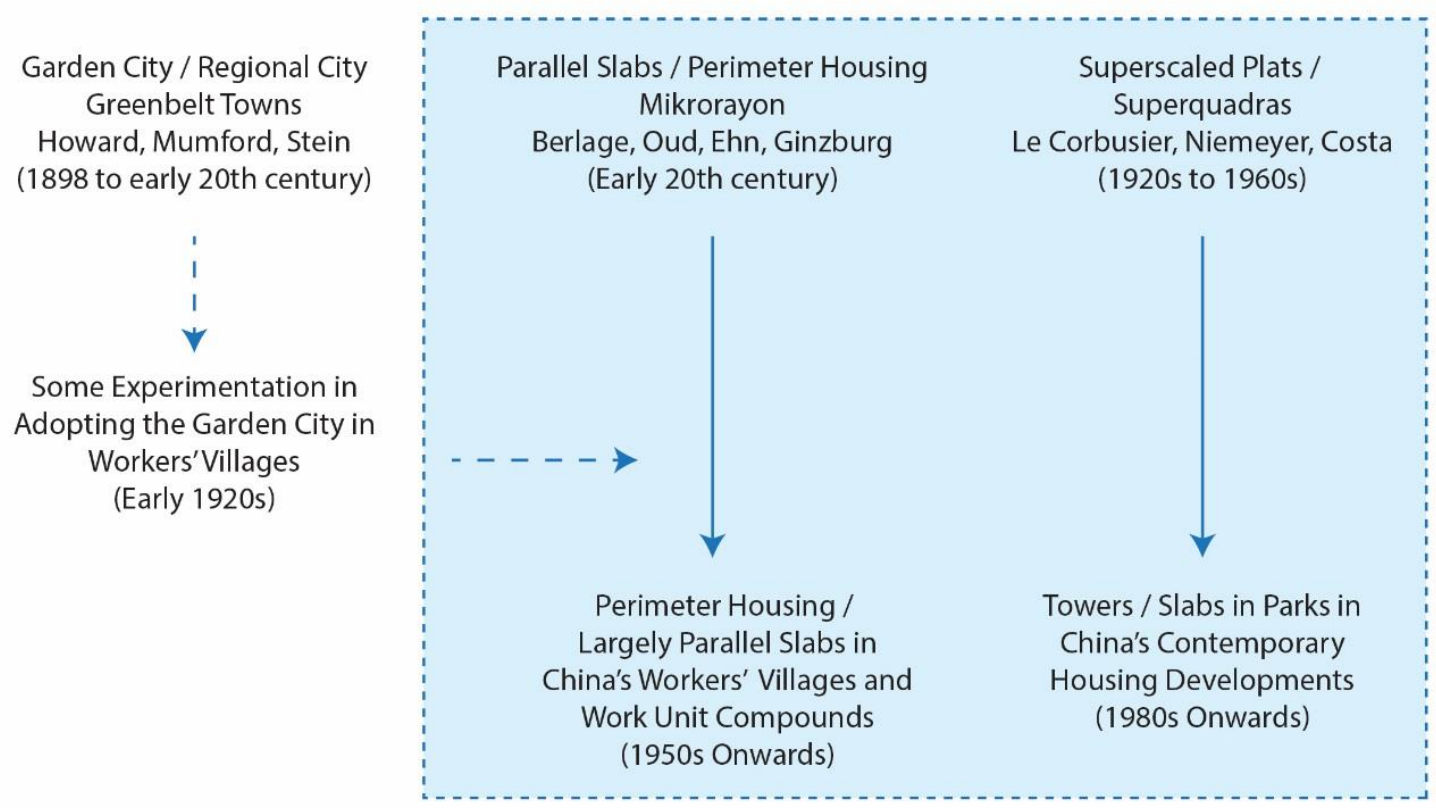

Two Dominant Strands in China

Source: Original diagram, drawing on work by Whiting 2004

Figure 2 turns to key neighborhood ideas in China: the planning idea of the neighborhood unit and the practice of neighborhood governance. The neighborhood unit, combining local, pedestrian accessible community and commercial services with a low-through-traffic design, was developed in the United States in the 1920s (Perry 1929; Carmona et al 2010). It had spread to China by the 1930s via the Japanese in Manchuria and then in the late-1940s by Chinese planners (Li 2013; Lu 2006). There it met a long tradition of neighborhood-level governance (Rowe et al 2016; Chan 1993).

The capacity for physical neighborhood design to generate strong social bonds has been rightly questioned; people can form and maintain relations at many scales. However, physical places have a role in connecting people to local services. In much of China, local governance also roughly matches the physical neighborhood giving the physical place a social reality (Li 2013; Rowe et al 2016). This is reinforced by the central government's support for both the superblock and for small-scale local-level governance - a practice that is pervasive and internationally distinctive (Read with Pekkanen 2009). 
The danwei or work-unit organization that prevailed from the late 1940s to the early 1990s was the basis of urban community formation and governance. Each danwei was not only the place of employment but very often was the place of welfare, health, education, culture, safety, and financial support to its workers. Many built their own residential compounds, creating livework communities that encompassed welfare, employment, and governance (Bray 2005). A system of governance that operated in parallel to the danwei from 1954 was the residents' committee, or the jumin weiyuanhui. Extending the reach of the Communist Party to urban residents and managing local affairs, each jumin weiyuanhui corresponded roughly to the neighborhood unit or xiaoqu boundaries (Read 2000; Webster et al 2002). With the dismantling of the danwei, the shequ or community emerged as the local administrative structure beginning in the 1990s. This state administration unit can correspond physically to three types of urban spaces: (i) a single danwei or work-unit compound, including the residential areas; (ii) a single xiaoqu or bounded neighborhood unit; or (iii) an urban block (Rowe et al 2016). Bonds in the current shequ or community are fostered through the social interactions in the local governance, as well as the common spaces of the neighborhood.

Today, residential complexes that were once part of a danwei now see many outsiders renting units on short-term basis, resulting in weaker community ties (Rowe et al 2016). By contrast, the classic neighborhood unit as conceived by Perry has no specific political structure tied to it (see Figure 2). Instead, it is built upon a physical combination of housing and services that would best suit families with children. Here, the primary school became the central institution in the "scheme of [spatial] arrangement for a family-life community" (Perry 1929). China's current superblock urban structure with strong neighborhood governance thus draws on international experience but also local traditions and Chinese-specific innovations (Nguyen 2013). While this neighborhood governance is widespread, it is also not uniform, varying in its degree of resident participation and provision of community and social services (Read 2008; Derleth and Koldyk 2004). 


\section{Figure 2: Neighborhood Practices in China Showing Functions Inside and Outside the Neighborhood (shaded)}

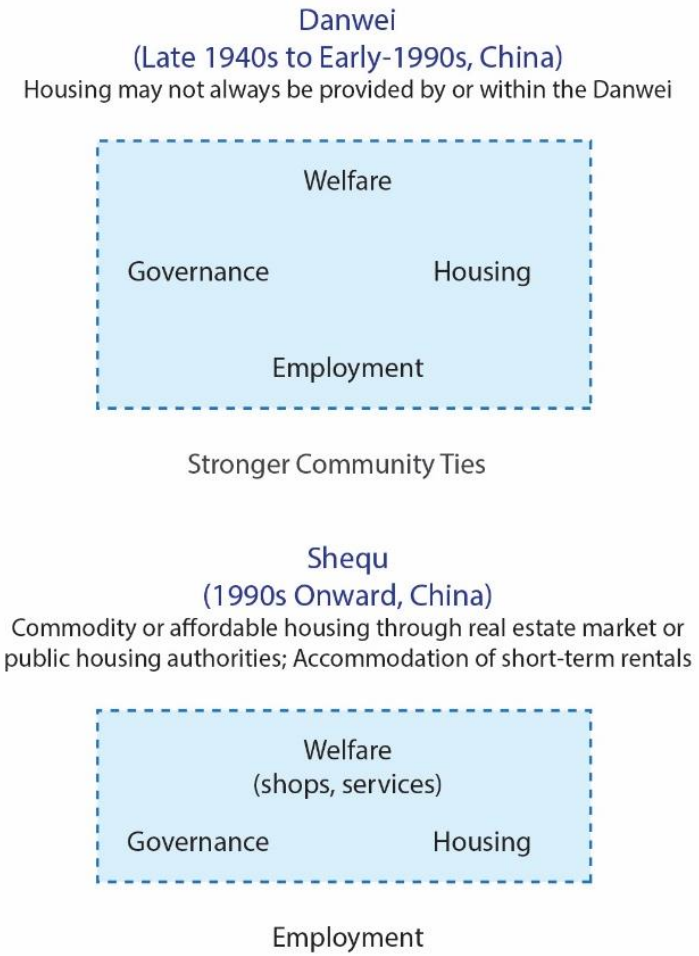

Weaker Community Ties

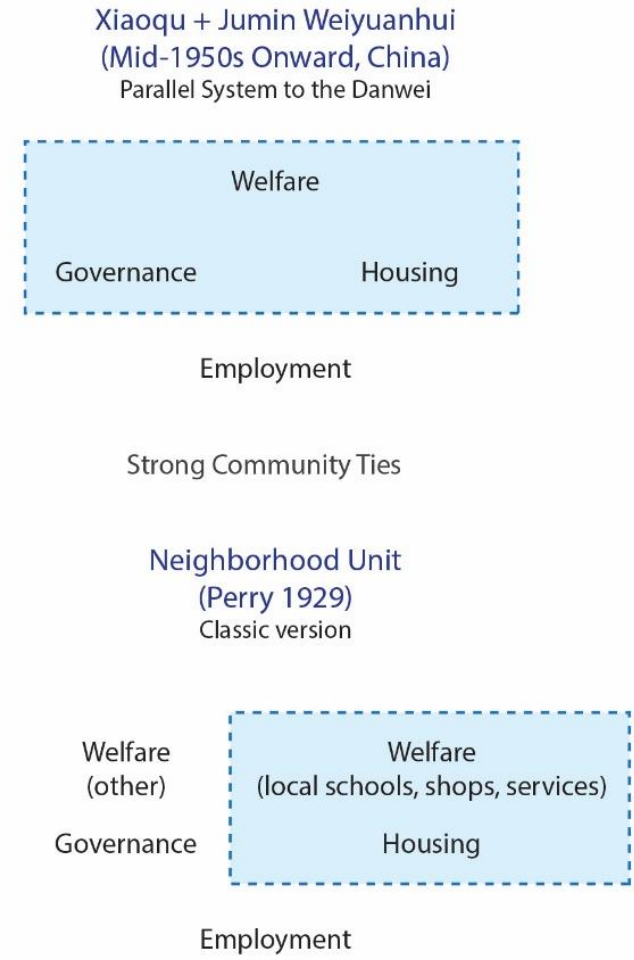

Still Weaker Community Ties

\section{Targeting the Bounded Superblock Neighborhood: New Planning Directives in China}

Despite the privacy afforded by the gated superblock and the economies of scale accrued (Gao and Zhang 2006), it has drawn considerable criticism from design and planning professionals over the past decade or so. Extensive discussions in both English and Chinese scholarship have raised several major shortcomings of the bounded superblock neighborhood.

First, the coarse-grained network of roads surrounding the mega-sized plots is more susceptible to traffic congestion as it is akin to a tree configuration, reducing through-traffic flows that would have been facilitated by a more fine-grained grid configuration (Alexander 1965; Sun 2007; Marshall 2005; Rowe 2011). This observation is in common with the critiques leveled against large urban blocks in other contexts such as Manhattan back in the 1960s (Jacobs 1961).

Second, the superblocks foster a sense of isolation from the surrounding fabric (Plunz and Sheridan 2006). In China, this is reinforced by block enclosures combining gates, fences, walls, or shrubs, creating both physical as well as symbolic barriers valued for the perceived security and social stability of a place ( $\mathrm{Li}$ and He 2015; Wei and Qin 2011). In reality, the barriers have 
been unable to offer safety guarantees and how much they limit access varies considerably from city to city (Miao 2003; Rowe et al 2016).

Third, the isolation in the tree configuration lends itself to a fragmented urbanism. Access within and between the blocks often entails indirect, circuitous routes for pedestrians, cyclists, and drivers alike. Amenities and services nested within the blocks are confined primarily to residents of the neighborhood and are often underutilized (Miao 2003; Li and He 2015; Sun 2007).

Fourth, the superblock enclosure has compromised the quality and vibrancy of adjacent streets. Walls, gates, fences, and shrubs create an unwelcoming, monotonous streetscape (Wei and Qin 2011; Sun 2007). Internalizing the neighborhood amenities and services diminishes opportunities for social interaction along the public streets surrounding these estates, often resulting in deserted sidewalks (Miao 2003).।

Fifth, roads between the blocks tend to be oversized with limited connectivity. Often, there is an arterial road with eight lanes or more every kilometer. Roads in Chinese cities also tend to have a lower number of road intersections and a longer distance between them as compared to European cities such as Turin, Barcelona, and Paris (World Bank and the Development Research Center of the State Council, 2014; Sun 2007).

Finally, it is much more difficult to convert part or the entirety of the block to accommodate a greater number and spatial array of uses because of the predominantly residential functions occupying these bounded developments. The superblock neighborhood's ability to adapt and be flexible to different functions over time is thus considerably undermined (Rowe 2011). 


\section{Figure 3: Comparison of Neighborhoods in China and Urban Block Structures Elsewhere}

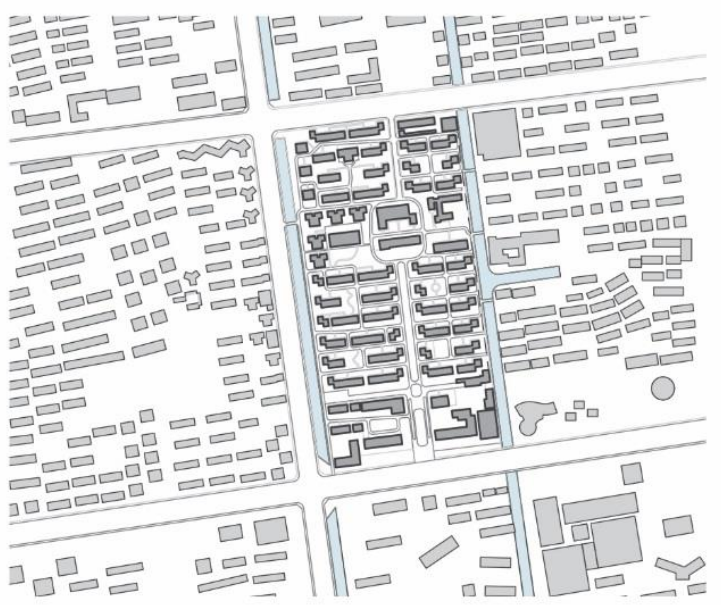

Caixiang Xincun, Suzhou

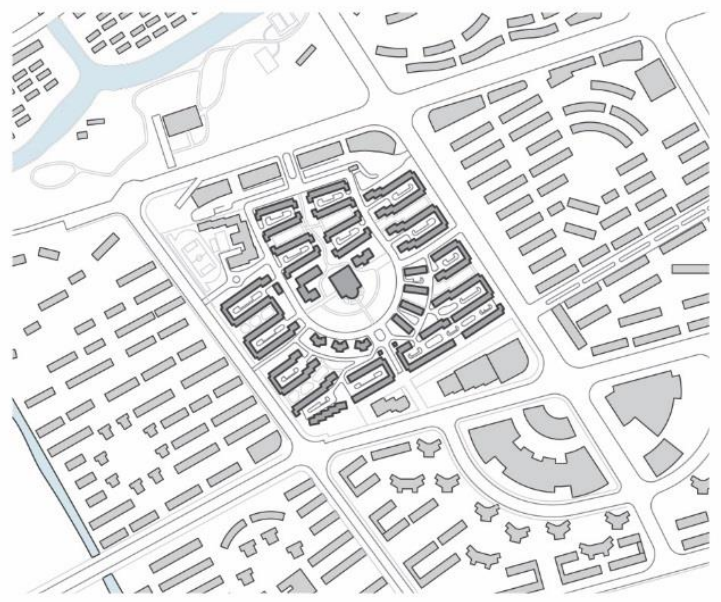

Sanlin Yuan, Shanghai

Block Comparison

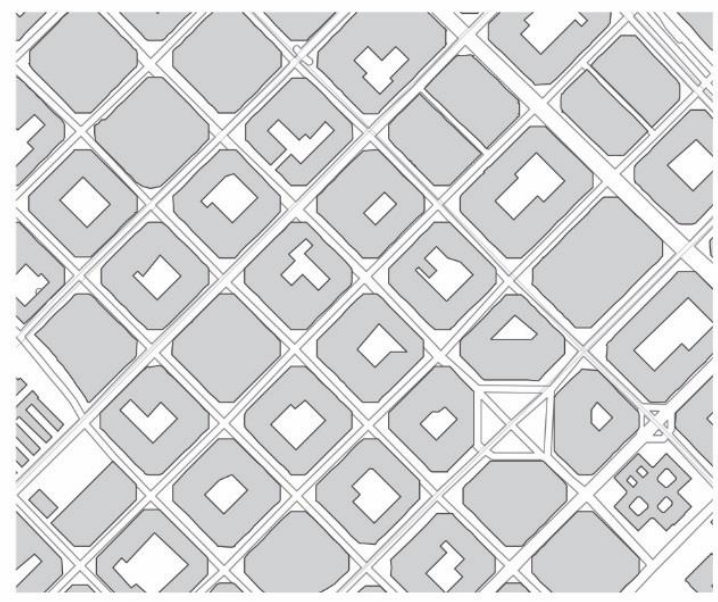

Eixample, Barcelona

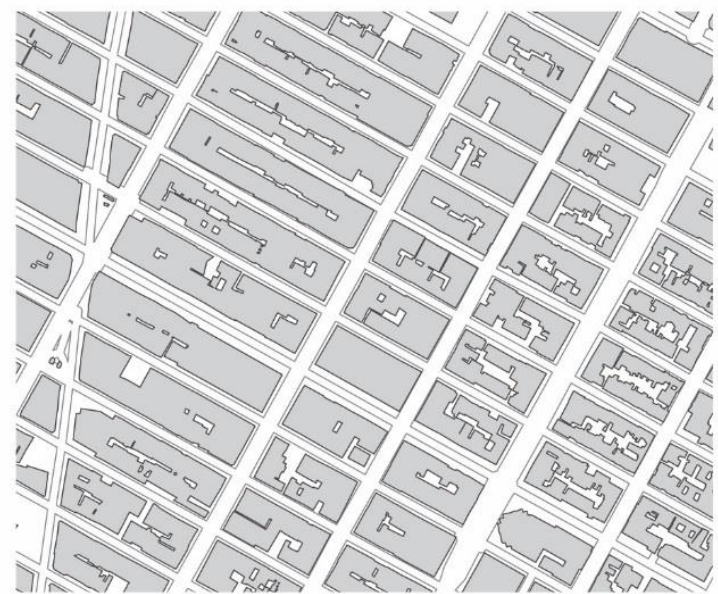

Manhattan, New York City

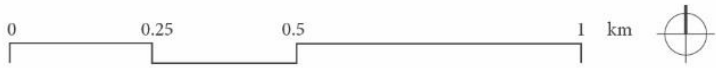

Using examples dealt with later in the paper, Figure 3 illustrates the differences between current superblocks and classic street grids deemed by Chinese planners to be mature types of urban block structures. The Chinese cases are from core city (Caixiang Xincun) and middle ring suburban locations (Sanlinyuan), though similar layouts are found throughout the metropolitan areas. The international cases are from core cities but reflect contemporary ideas about grid block structures proposed for a variety of metropolitan locations. Key design issues for the Chinese cases include comparatively oversized urban blocks, coarse-grained road networks, and poorer urban connectivity, especially in the Caixiang Xincun and Sanlinyuan cases. What is less apparent from the figure are the strong block boundaries and internalized amenities and services. 
The central government of the People's Republic of China has been aware of these problems. According to the State Council-the highest organ of administration and executive power in China - the changes in the newly-released guidelines are intended to address "obvious issues" and "urban ills" such as traffic congestion, the lack of openness and accessibility, and the profligate use of land, among others (Communist Party of China Central Committee 2016).

The last time such guidelines were put in place, in 1959, they defined the parameters for planning and design practice through most of the 1960s and into the 1980s. The recent reforms covering more than a hundred suggestions in 27 areas thus have similar potential. Table 1 lists the guidelines relevant to the "enclosed residential neighborhoods" and "work unit compounds."

\section{Table 1: State Council Guidelines to Create a Refined Urban Block and Street Network}

\section{Guidelines from Paragraph 7}

[1] Reinforce planning and construction of a refined urban block structure. Clearly distinguish areas of newly constructed urban blocks in a hierarchical manner, developing open, convenient, appropriately-scaled urban blocks.

[2] Establish an urban road layout comprising "narrow roads and a dense network of streets", and construct an urban road system that appropriately combines expressways, arterial roads, collector and distributor roads, as well as local streets.

[3] New residential neighborhoods must expand the urban block structure. In principle, enclosed residential neighborhoods are not to be built.

[4] Existing residential neighborhoods and work unit compounds have to be gradually opened. Transform internal streets into public ones, resolving street layout problems and promoting efficient land use.

[5] Open up various types of "dead-end roads," forming a complete street network, improving overall road connectivity.

[6] Scientifically and systematically install traffic safety and management facilities, enhancing roadway safety.

[7] By 2020, increase the average road network density to $8 \mathrm{~km} / \mathrm{km}^{2}$ in urban built up areas. Roads should constitute up to $15 \%$ of the land use area. ${ }^{1}$

[8] Actively adopt one-way streets to organize traffic.

[9] Construct bicycle lanes and pedestrian networks to promote green mobility.

[10] Appropriately allocate parking facilities, encourage public-private (social) partnerships, relax market barriers, so as to gradually alleviate the parking problems.

${ }^{1}$ According to the China Urban Planning and Design Research Institute, as of 2016, roads constituted approximately $12 \%$ of the land use area in built-up areas (Huang 2016). 


\section{Policy Implications: Opportunities \& Challenges}

Since the guidelines were introduced, experts from the China Urban Planning and Design Research Institute and the National Development Reform Commission, as well as Chinese scholars, have largely expressed their support. In their opinion, the reforms would help to transform Chinese cities into "truly modern ones that are open and defined by their public places and services" (Xinhua News 2016b). By increasing the street density and creating a fine-grained network, Chinese cities would improve land utilization and urban convenience, providing for smaller-scaled and more diverse businesses, amenities, and services (Xinhua News 2016b). Some experts have suggested that there ought to be a transition phase to prepare and implement complementary policies that would address the potential tensions arising from the guidelines (Guangzhou Daily 2016). Complementary policies relate to property management, security, and property rights, as well as the planning and allocation of public amenities and services (Han and Wang 2016).

To realize these policies would involve multiple stakeholders: the Ministry of Housing and Urban-Rural Development; the Ministry of Law; the State Council; the National People's Congress; planning commissions and bureaus from the provincial to local district levels; real estate developers; property managers; neighborhood small and medium businesses; sub-district offices and local community service providers; and residents' and homeowners' associations. So far, Beijing has taken the lead in testing implementation of these guidelines. The Beijing Municipal Planning Commission will be classifying various Beijing neighborhoods according to their types, ages, and the degree of development in the broader vicinity. In addition, pilot projects will be carried out as part of the planning of Beijing's administrative sub-center located in Tongzhou where urban blocks will be in the range of 100 to 200 meters in width (Kong 2016).

Overall, the policies present opportunities and challenges across three different but interrelated areas: (i) design and planning; (ii) law and property rights; and (iii) sociopolitical realities in the neighborhoods. The following section is organized into a discussion along these three areas. While it may seem more straightforward to rework the bounded superblocks from a design perspective, the greater challenge lies in reconciling the tensions between the existing property owners and the local planning agencies because of the property rights issues and the sociopolitical realities in the neighborhoods.

\section{(i) Design and Planning Implications}

In urban design terms, China's recent reforms promote the grid, turning away from the rigid and disconnected tree structure towards a semi-lattice structure that is a closer reflection of the complexities and overlaps in a living city (Alexander 1965; Marshall 2005). The new policies offer both opportunities and challenges along two distinct planes: (a) the design of new, possibly smaller-scale residential neighborhoods; and (b) how to retrofit existing superblock neighborhoods and work unit compounds. The latter arguably poses greater challenges but, in the same token, also offers more urban design opportunities for innovation if well-executed. By drawing on case studies of a new development and three mature neighborhoods, this section seeks to provide discussion by offering possible interventions to create more open superblocks.

\section{(a) Design Implications for New Developments}


In comparison to retrofitting existing neighborhoods and compounds, designing new blocks and neighborhoods at a smaller scale is more straightforward. There are, however, several key points to bear in mind.

- A careful balance needs to be struck between creating a uniform urban grid for easy navigation and providing various block sizes for architectural diversity.

- In the guidelines, vehicular navigation also seems to be prioritized over pedestrian links. Within a superblock pedestrians are often well catered to. Hybrid models like the fused grid that maintain good pedestrian links while calming vehicular traffic are worth investigating (Grammenos 2008).

- Within the smaller blocks, planning agencies could still permit multiple developers within a single block. This supports a mixture of uses, integrating different buildings into a site, rather than having only one dominant structure (Love 2009).

- An advantage of the superblock configuration is its flexibility to incorporate multiple subdivisions, uses, and developers. China thus should not be too quick to discard all superblock development; balancing smaller blocks in an urban grid with the potential for aggregation when needed.

- New developments should also pay equal attention to the urban design of the streets - the spaces in between the blocks that shape the quality of urban life as much as the blocks themselves (American Planning Association 2016; Jacobs 1993). For example, a street wall of shops can engage and enliven the public realm to overcome what Jane Jacobs (1961) refers to as the "border vacuum." This would be a departure from conventional road planning in China which has emphasized transportation functions and performance of the network (Liu et al 2016; Dong et al 2013).

Since the early 2000s, China has seen several development projects that have successfully reintroduced fine-grained blocks and more permeable streets. These have tended to be mixed use redevelopments of existing superblock structures and former work unit compounds such as the Shougang Factory in Beijing (Shougang Group 2014), but also included plans for new towns like Chenggong in Kunming (Luo et al 2011). A prominent development that dealt creatively with introducing greater porosity to the superblock is Jian Wai SOHO, a mixed-use live-work environment housed in elegant towers along the Tonghui River in Beijing. This complex of high-rise small offices and home offices, as well as low-rise retail and commercial "villas," is part of a larger project that broke down a 34-hectare superblock of old factories into smaller parcels, supported by a new network of arterial roads and secondary streets. The result is an open, accessible, and pedestrian-friendly urban block with a full street network improving the overall road connectivity in the area. These changes are aligned with several of the State Council guidelines, including "distinguish[ing] areas of newly constructed urban blocks in a hierarchical manner" and "developing open, convenient, and appropriately-scaled urban blocks" (Communist Party of China Central Committee 2016). The most outstanding design feature specific to the project is a "field operation" which comprises a horizontal ground plane of walkways crisscrossing the site, punctured strategically by an array of sunken courtyards that serve as recreational spaces and vertical access routes to the underground carparks and tower lobbies (Rowe and Kan 2014).

Due to its prime location in the Beijing CBD area, the Jian Wai SOHO project became so 
successful that many of the live-work residential units were converted into office space, reducing its mixed-use character. Interviews conducted with users in the summer of 2014 revealed that the project is perceived as one that is "open to the public, and while it is not gated at all, the development is very safe". Interviewees also thought that within each of the smaller urban blocks, the "separation between pedestrian and vehicular circulation made it safe for pedestrians at the ground level". The project has been supported by an adequate number and variety of retail stores and amenities both within the block and along the streets, thereby enlivening the public realm and reducing the "border vacuums" between the blocks. One shortcoming, though, as the interviewees pointed out, was that these mostly catered to the office crowd, resulting in the lack of supermarkets or grocers for the smaller proportion of residents (Harvard University Graduate School of Design Health and Places Initiative 2016). This is notable as it highlights the importance of allocating complementary amenities and services in the interest of both the community and the public. Overall, however, the effective transformation of an unwieldy factory superblock compound into the fine-grained complex of accessible urban blocks in Jian Wai SOHO offers a useful basis to explore further interventions in redesigning the superblock in the future. 
Figure 4: Jian Wai SOHO and the Original Superblock Factory Compound Before Redevelopment
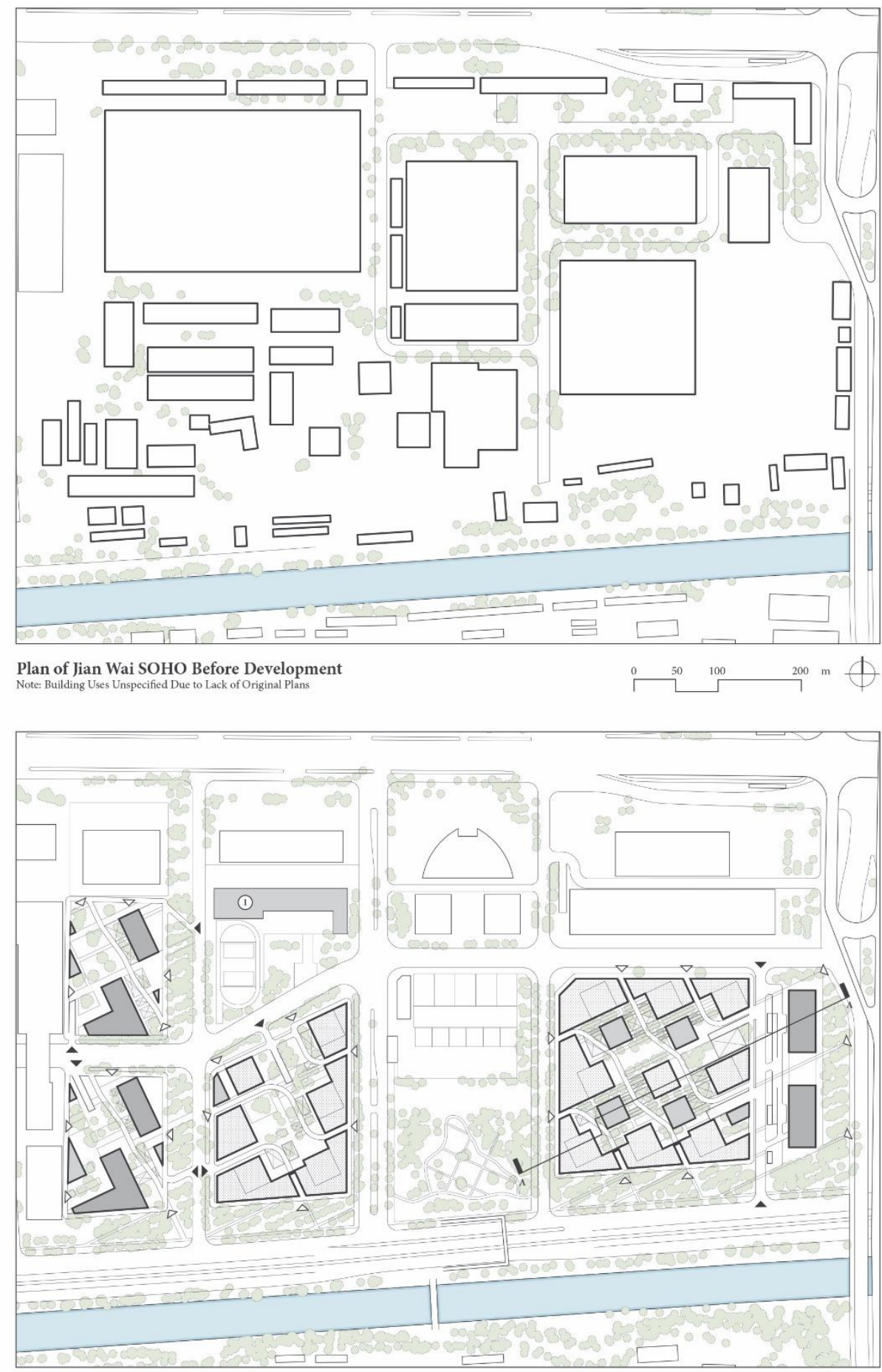

School

Plan of Jianwai SOHO After Redevelopment

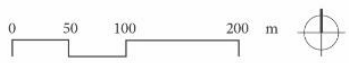

Open-to-below

Residential +

Mixed Use

Non-Residential,

Retail

Office Block

$\square$ Water Body

Vehicular Entry

$\triangleright$ Pedestrian-only Entry 


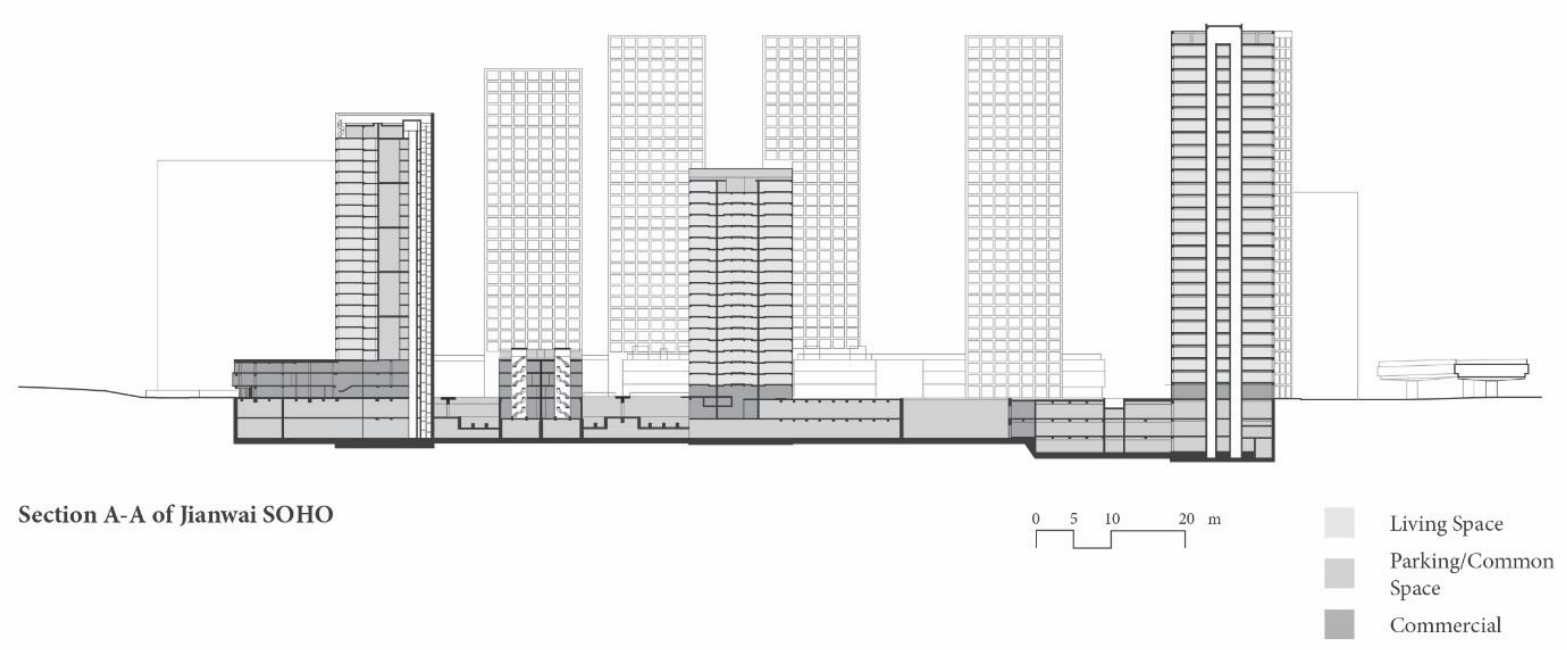

(b) Retrofitting Existing Superblock Neighborhoods \& Larger Work Unit Compounds

For existing superblock neighborhoods and larger work unit compounds, the State Council's suggestion of opening them up and putting in smaller, public streets may appear to be a clear-cut strategy. In reality, the varying degrees of gatedness and the different types of superblock configuration pose different retrofitting challenges. Moreover, to adapt a segregated urban environment into one that is integrated is more challenging than designing a completely new development. Here, the authors offer proposals for retrofitting specific blocks that represent different urban types common in China: (i) perimeter commercial blocks with minimal limits to entry; (ii) bounded superblocks without gates; and (iii) completely bounded and gated superblocks. Many of the issues raised in retrofitting are also pertinent to new developments, but the mixture of challenges is more complex.

For perimeter commercial blocks such as Tongfangxiang Xiaoqu (Suzhou), the modifications based on the new guidelines would be relatively minimal. As the project already has two gated roads cutting through the block in the north-south and east-west directions, it would be a matter of removing the gates and opening the interior roads for through traffic organized by a roundabout in the center of the neighborhood. 
Figure 6: Plan of Tongfangxiang Xiaoqu

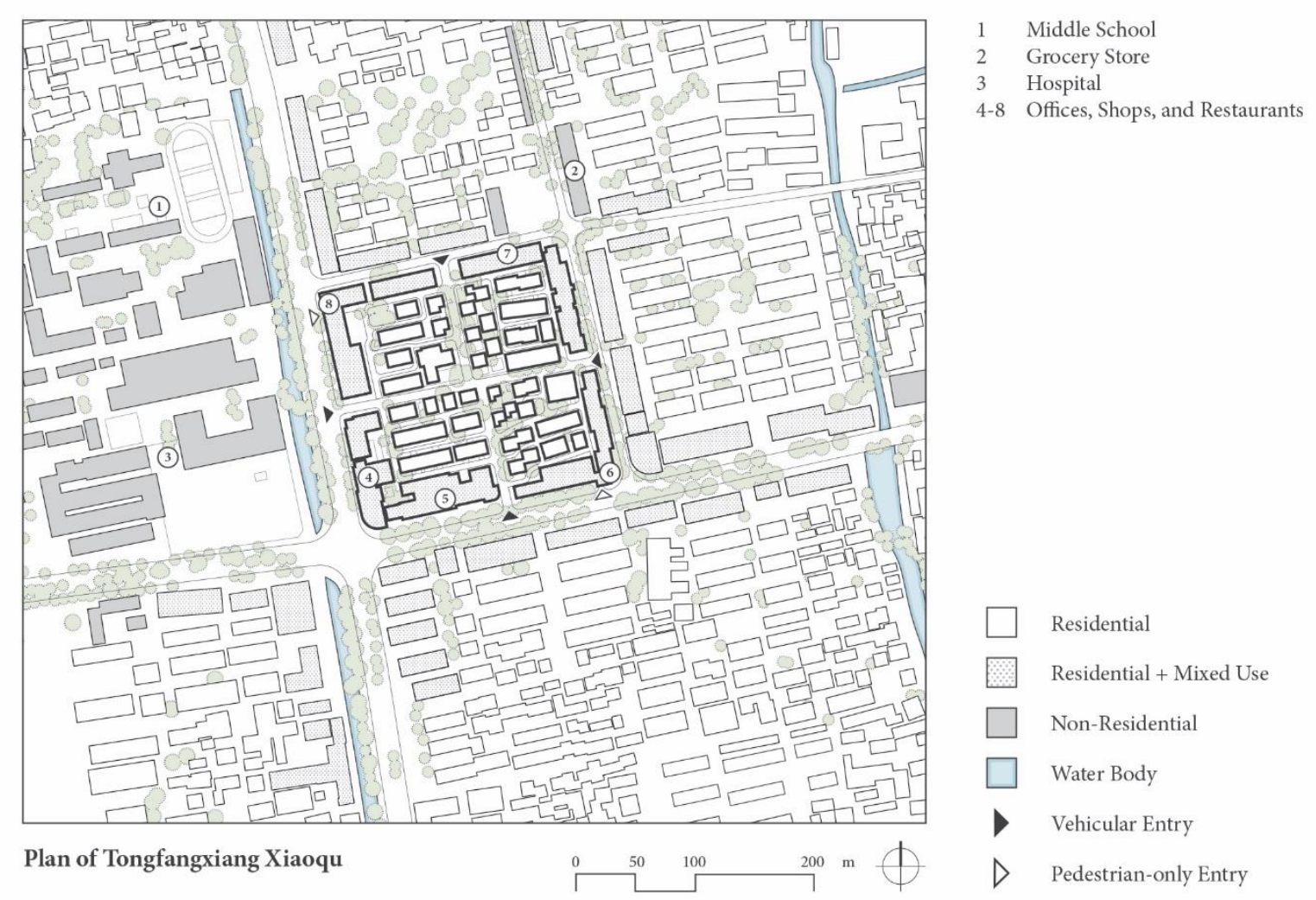

For bounded but not gated superblocks that already permit vehicular traffic through neighborhoods, the guidelines may necessitate a mixture of both improved pedestrian and vehicular access. As prototype simulations of redesigned superblocks by Mah and Villoria (2016) suggest, increased access can in fact be attained through the introduction of relatively few new openings. In the case of Caixiang Xincun (Suzhou) which is walled and separated from its surroundings by canals on the eastern and western edges of the block, any interventions would be in the form of creating one or two additional vehicular and pedestrian access routes across the canals to enhance the east-west permeability. The improved public access would also increase the use of semi-public services originally internally-oriented towards the local residents.

For these two types of superblocks, it is important to ensure that traffic safetyparticularly for pedestrians and bicyclists - is not compromised. Although the directives acknowledge the need for traffic calming measures, their main goal, it seems, is improved road connectivity. As such, it is crucial that traffic calming measures are prioritized. These could include pedestrian-oriented features such as sidewalks, raised crossings, and others that slow traffic, like bulb outs and speed tables. 
Figure 7: Plan of Caixiang Xincun and Proposed Changes

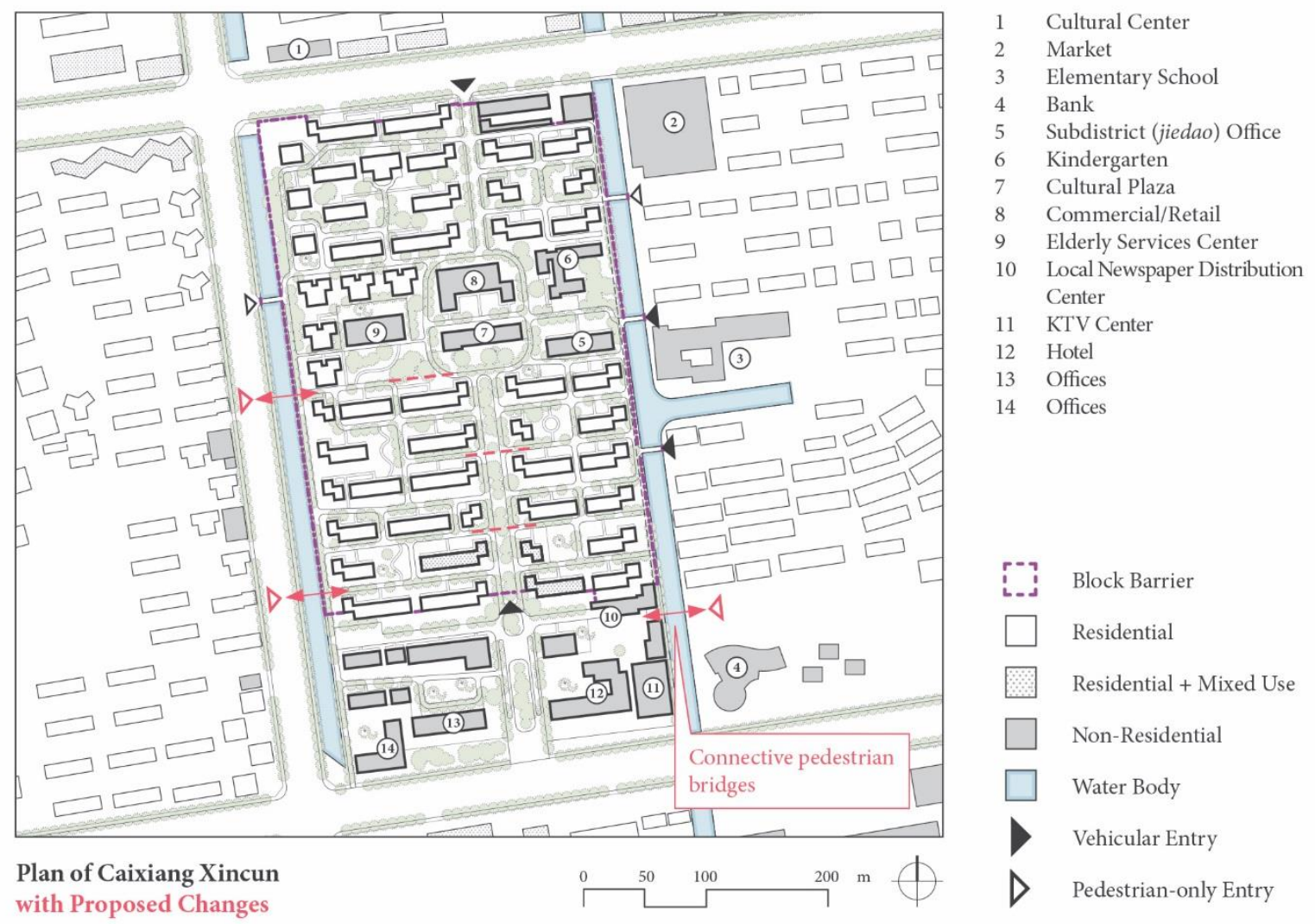

Completely gated, walled, and guarded superblock neighborhoods, on the other hand, require a comprehensive set of interventions beyond the mere removal of the gates and guards. It requires reconfiguring road and pedestrian networks within the block, creating streetscape along newly-opened thoroughfares, and potentially relocating internally-oriented programs and services such as grocery stores, community centers, cafes, and restaurants. For neighborhoods that are of the "towers in the park" or "slabs in the park" variety, cutting a public right-of-way through the blocks would need to address the issue of compensating for the lost green space and the question of how to use newly accessible space where buildings are set back far from the street behind landscaping, parking, or internal roads. This could include permanent infills, such as podiums or walkups, or programming the open spaces with markets, performances, events, and festivals. The key is to avoid a heavy-handed approach to opening more public vehicular right-of-ways and connecting "dead-end roads".

An example from Sanlinyuan in Shanghai shows some of these issues, where the internal road network would have to be expanded to accommodate more through-traffic, and new entry points created for vehicular and pedestrian access. To encourage "green mobility," bicycle paths could also be introduced to connect the estate to the surrounding neighborhoods. A heavyhanded approach to provide more direct through roads in Sanlinyuan would entail creating new cross streets and relocating the community center in the middle of the estate. In comparison, lighter interventions would retain the existing roadways and focus more on increasing their capacity without any major alterations to the road network and building layouts. 
Figure 8: Plan of Sanlinyuan and Proposed Changes

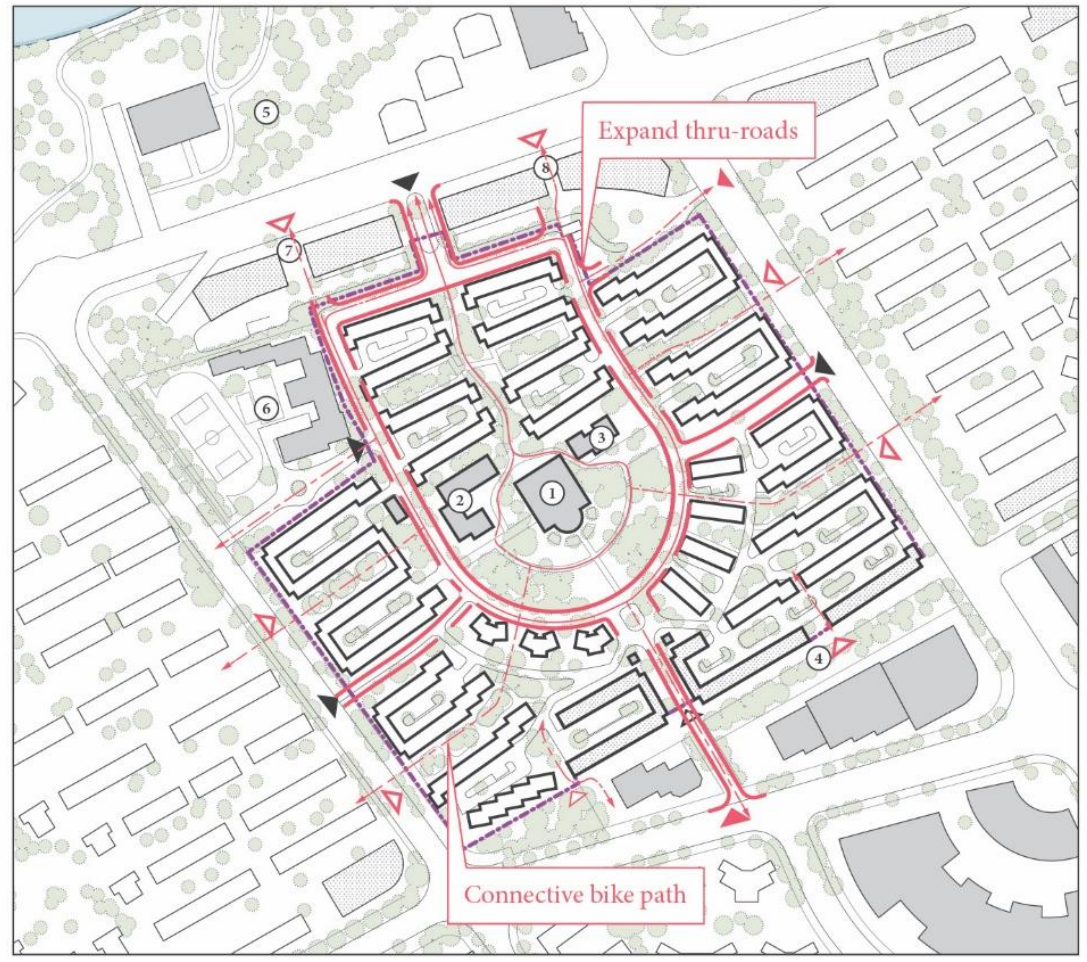

Plan of Sanlin Yuan

with Light-Handed Changes
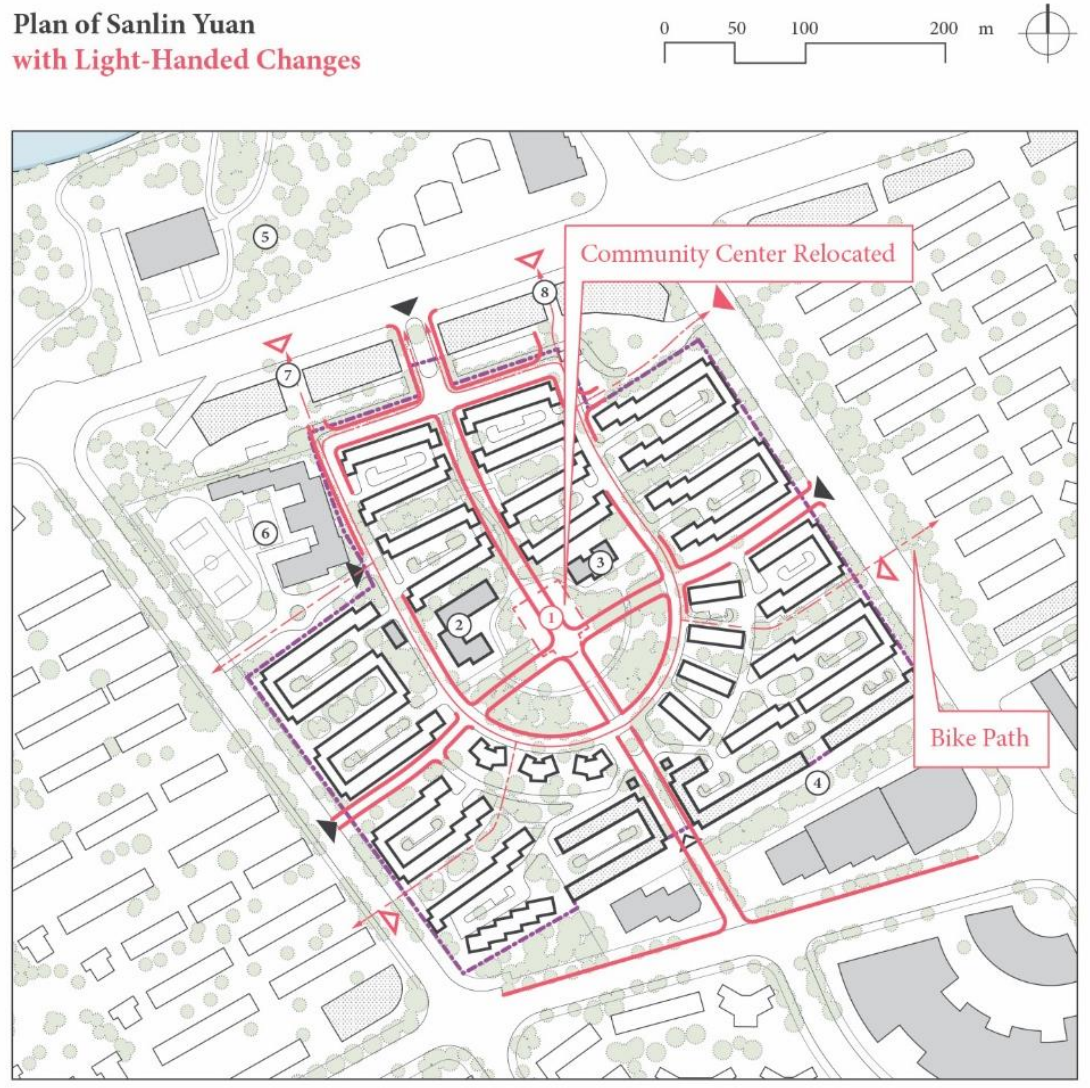

Plan of Sanlin Yuan

with Heavy-Handed Changes

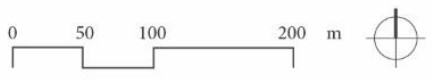

[.] Block Barrier

Residential

Residential + Mixed Use

Non-Residential

Water Body

V Vehicular Entry

D Pedestrian-only Entry Relocated

2 Preschool

3 Subdistrict (jiedao) Office

4 Commercial Area

5 Park

6 Elementary School

7 Shops and Restaurants on Ground Floor

8 Shops and Restaurants on Ground Floor

Block Barrier

Residential

Residential + Mixed Use

Non-Residential

Water Body

V Vehicular Entry

D Pedestrian-only Entry 
In the above proposals, we have not defined whether the new or retrofitted roads ought to be one- or two-way streets. Despite the State Council's call for the active adoption of one-way streets, one-way streets also have their shortcomings. One-way streets can pose additional safety issues because of increased vehicular travel speeds and navigational confusion. Overall, one-way streets work best in downtown or heavily congested areas, as well as in "pairs" or "couplets", separated by an urban block of no more than 400 meters (U.S. Department of Transportation Federal Highway Administration 2016). What is perhaps instructive for China is that some North American cities like Denver, CO; Tampa, FL; Sacramento, CA; and Louisville, KY, have begun to convert their traditional one-way streets to two-way operations. Two-way streets help to create higher levels of economic activity, calm traffic, support increased traffic volumes, and reduce traffic collisions (Gayah and Daganzo 2012; Gilderbloom and Riggs 2015). Two-way networks can be safer and more efficient, offering higher trip-serving capacities despite lower vehiclemoving capacities (Gayah and Daganzo 2012).

\section{(ii) Legal and Property Rights Implications}

As of December 2016, the guidelines have been deemed to be policies at the Party- and state-levels. According to the Supreme Court of the People's Republic of China, the reforms would still have to be legalized because they implicate property rights issues related to the affected owners and business operations (Li 2016). Article 73 from the Property Law of the People's Republic of China makes two exceptions regarding ownership rights in a residential, work unit, or commercial compound: public roads and public green spaces belonging to a city or township. All other public spaces, buildings, or rooms used for property management within a neighborhood are jointly owned by all the owners (National People's Congress 2009). For existing enclosed superblocks, the physical changes of converting what were once roads and spaces under joint ownership into public ones raises important questions of rights and compensation. Negotiations would be needed amongst the property owners, and between the property owners and the local planning bureaus. In Sanlinyuan, for instance, other than attaining a consensus across more than 2,000 households, any interventions would also entail engaging the Sanlin Residents' Committee (jumin weiyuahui), the Sanlin Community (shequ), and the Pudong New Area Planning and Land Authority.

In addition, multiple layers of rights exist in China. The Constitution of the People's Republic of China, and the land laws, state that land in urban areas is owned by the government. The state may, in the public interest and in accordance with the law, expropriate or requisition land for its use and make compensation (National People's Congress 2004). As such, in existing residential superblocks and work unit compounds, what the individuals and institutions hold are land-use rights granted for a limited term. The state can therefore expropriate, without challenge, the land granted to individual owners and work unit institutions for the purposes of urban infrastructure (Wong 2015). The State Council's design guidelines bring into direct conflict these public versus private interests. A process of adjudication and fair compensation will be needed to minimize land disputes that have been a major cause of mass incidents in China.

Even if the property owners agree to transferring property rights and opening internal roads to public use, as desired by the guidelines, local municipalities may not be willing or able 
to shoulder the costs of the compensation, construction, and subsequent maintenance. With the decentralization of powers in China, local municipalities have experienced increasing fiscal and administrative obligations without corresponding rises in tax and other revenue streams (Lan 2012). According to recent estimates, local governments receive slightly over half the fiscal revenue but shoulder more than 80 percent of the expenditure (Wei 2016). They have borrowed substantially to finance public infrastructure improvements and other capital investments, resulting in debt levels at almost 40 percent of China's GDP (Wei 2016; Wu 2016). It is thus doubtful whether local governments have the financial capacity to realize the State Council's guidelines.

\section{(iii) Sociopolitical Realities}

A related hurdle is the cultural perception of security and safety associated with gating and other forms of enclosure. Early studies by Chinese researchers found that the gate was preferred by residents not only because it enhanced the sense of security, but because it could minimize disturbance by peddlers, and unwanted door-to-door sales, as well as to reduce noise pollution from through-traffic (Ni 2000; Jia \& Wang 2001). Enclosed neighborhoods also continue a tradition from pre- and early-modern times, such as the gated wards of Qing dynasty Beijing and the bounded compounds of Communist work units (Dray-Novey 1993; Bray 2005).

This strong penchant for gating is reflected by the public's concerns about neighborhood security in the wake of the State Council's new guidelines. This prompted the Vice-Minister for Housing and Urban-Rural Development to clarify that the initiatives to "open up" existing enclosed neighborhoods and work unit compounds were "not intended to remove their walls", but to "open the gates" instead (Wu 2016). Although the clarification itself is still somewhat vague, it suggests that the new guidelines will not necessarily usher in the end of gating as a practice. The preference for walls and other types of enclosures further imply that the isolationism and border vacuums between blocks may continue to be perpetuated, and perhaps reinforced, albeit at a smaller scale.

New developments are, however, likely to introduce smaller blocks with a denser road network. Whether they will have open, porous blocks like Jian Wai SOHO is another question altogether. The case of Linked Hybrid, a residential mixed-use development in Beijing designed by Steven Holl, is an illustrative case. Holl's original intention was to achieve "maximum urban porosity" through a mix of commercial functions on the ground floor servicing both residents and the public (Holl 2009). The Linked Hybrid, however, eventually saw the construction of a wall around its perimeter, reinforcing the exclusivity of the ground floor programs and the project as a whole (Rowe and Kan 2014). Institutional and financial barriers notwithstanding, what is perhaps a greater hurdle to the successful implementation of an open design and the sale of such new developments is the proclivity for gating and maintaining a sense of physical security.

Moreover, in the high profile, large-scale projects to date, there has been the tendency to turn to renowned international architects and planners such as Yamamoto, Holl, Peter Calthorpe, and Johnson Fain \& Partners to forward the agenda for smaller, open urban blocks. The reality is that until this design/planning approach has gained more traction domestically, not many of the 
cities or developers will have the incentive or financial capacity to engage these foreign practices.

Resistance to opening public rights-of-way may also come from large work unit compounds occupied by institutions and state-owned enterprises. Since the work unit system was established in the 1950s, each enterprise provided housing and other non-residential services for its employees. Many of these work unit compounds have been built as walled, gated, and guarded blocks (Bray 2005; Lü et al 2001). For instance, in Beijing's Haidian District - the city's education and research hub-road connectivity is impeded by the high concentration of gated campuses that range from 28.8 hectares at the China University of Mining and Technology to a sprawling 395 hectares at Tsinghua University. The challenge here is less about how to redesign these compounds and more about how to obtain the consensus from these politically powerful institutions and enterprises to permit some degree of public vehicular and/or pedestrian access through their grounds. It is, of course, not an impossibility, as demonstrated by the CCTV/TVCC Media Park project by OMA which emphasized the design of an open public realm as part of its broader complex, but it will be an uphill climb.

Finally, initiatives such as connective bicycle lanes and walking paths may not be as easily implemented despite the environmental and health benefits. Residents and users in existing superblocks may find these types of infrastructure intrusive, even if infrastructure can help to enhance overall safety for all road users (Marshall and Garrick 2011). The issue of public and/or private use-rights is also potentially more ambiguous for these two mobility networks that are integrated within the superblocks, as in the case of Sanlinyuan with its light-handed changes. It again raises a number of questions: who possesses the rights, who will be responsible for the construction and maintenance, and how might these networks compromise the local security? These design interventions are unlikely to challenge the local governance structures. However, they may well introduce more tensions between these structures, such as the residents' committee and the sub-district offices that are not integrated into the planning process, and the local planning bureaus tasked with implementing the guidelines.

\section{Tempered Approaches}

The subset of measures introduced by China's State Council targeting the gated superblock neighborhoods and work unit compounds imply a transformation of the current coarse-grained network of superblocks and wide streets into a finer-grained network of smaller urban blocks within a mesh of hierarchically-organized streets. While they are laudable for their intentions to improve road connectivity and different modes of access, this paper has argued for more tempered, light-handed approaches and cautioned against a complete rejection of the superblock. Overly prescriptive blueprints, like this comprehensive list of state guidelines that attempt to provide a "blanket rule," have substantial limitations. Instead, local stakeholders and agencies could have leeway to plan and design for the needs of their locale. The varied existing bounded neighborhoods and enclosed work unit compounds mean there will not be any 'onesize-fits-all' solutions. Suggestions to "actively adopt one-way streets," "open up various deadend roads," and to "transform internal streets into public ones" warrant more circumspection given recent studies that have cast doubt on their benefits and efficiency. Implementing these directives also raises other questions: Which are the agencies that will exercise oversight and 
coordination over the process of creating a hierarchical street system and ensuring an optimal arrangement of roads and one-way streets? Who will bear the costs of the road work, street improvements, maintenance, and property compensation? How will the modifications be phased?

From an urban design perspective, several additional issues need to be considered. First, the quality of the additional or modified thoroughfares is crucial. Thoughtful, well-executed street design matters in creating attractive public realms for users with different needs, and the directives clearly present an opportunity for enhancing the livability of these neighborhoods and compounds.

Second, increases in road network density should not be blindly pursued at the expense of traffic safety. Cities will be under pressure to achieve the goal of attaining an average road network density of 8 kilometers/square kilometer in urban built up areas by 2020. In reality, this will be a tall order for more than 303 out of 340 prefecture-level cities with current road network densities of 0.67 kilometers/square kilometer or less (Zhang et al 2015). In the haste to introduce new public rights-of-way, traffic calming interventions should be equally prioritized to ensure the safety of pedestrians and bicyclists.

Third, despite the shortcomings of superblocks, urban designers and planners should not be too quick to discard them as they have advantages. In Barcelona, for example, a new mobility plan unveiled in 2016 will create superblock neighborhoods (superilles) based on every 9 blocks in the existing Cerdà grid. This proposal emerged amidst concerns about overbuilding, a shortage of green space, an increasing desire to distinguish between residents and outsiders, and the general lack of utility in the Cerdà grid. The aim of this maxi-grid structure is threefold: (i) to reduce traffic, restricting vehicles to the superblock perimeter and permitting access by resident or service vehicles only at greatly reduced speeds; (ii) to free up some 60 percent of the streets into "citizen spaces" for culture, leisure, and community within each of the superilles; and (iii) to reduce excessive air pollution and noise levels caused primarily by traffic (Bausells 2016). China's existing superblock configurations in fact fulfill the goals that the superilles are now setting out to achieve and should be given due credit for these strengths and more. Other advantages of the Chinese superblock include a sense of privacy, a reduced need for public investment in communal amenities and services, and, in general, tranquil, pedestrian-friendly residential settings. As such, the State Council's guidelines ought to be approached and adopted with care. 


\section{Figure 9: Current Cerdà Grid and New Superblock Proposal in Barcelona}

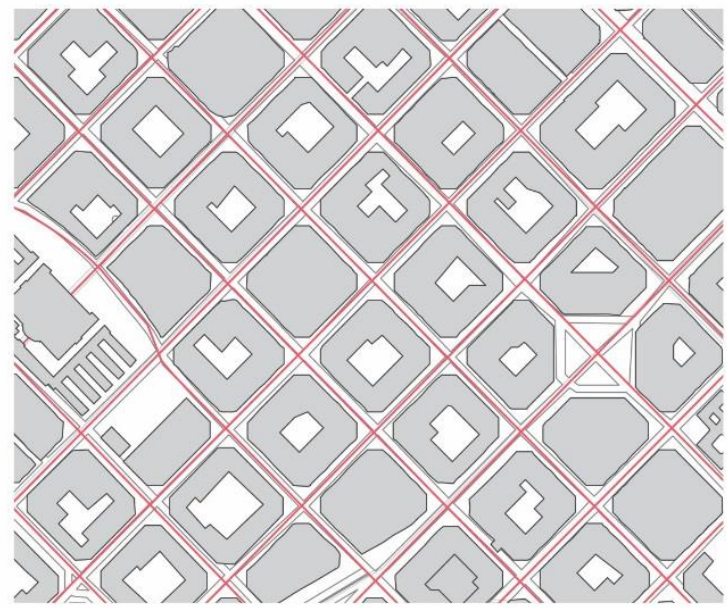

Eixample, Barcelona

Barcelona Superblock Proposal

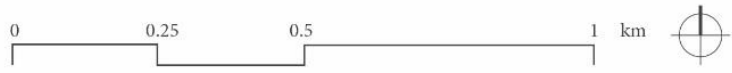

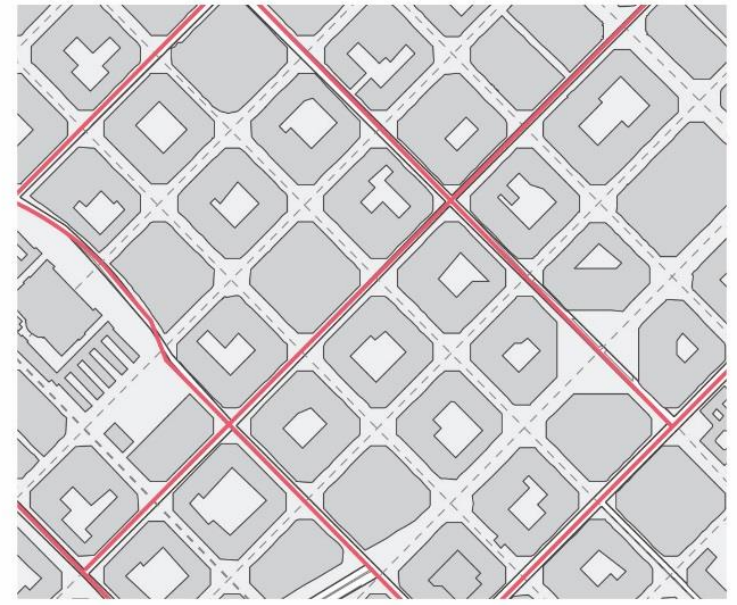

Eixample, Barcelona with Superblock

Public transport and cars at $50 \mathrm{~km} / \mathrm{h}$ Pedestrian and private vehicles at $10 \mathrm{~km} / \mathrm{h}$

Lastly, the heart of these directives targeting the closed superblock and compound is not just creating a fine-grained structure of smaller blocks and dense network of roads. Rather, it is about accommodating the increasing vehicular traffic in China's cities. Some of this may certainly be on-road public transport, as other guidelines by the State Council seek to prioritize public transportation and increase its modal split to between 20 and 40 percent by 2020 (Communist Party of China Central Committee 2016). On-road bicycles may also benefit from more direct routes and route options that can avoid the busiest streets. Unless, however, there is a concerted effort to curb the insatiable automobile appetite, no amount of block and street network reconfiguration will ease the country's growing traffic and air pollution woes in its cities. 


\section{Acknowledgements}

Thanks to the reviewers for their invaluable feedback and suggestions. Justin Kollar from the Harvard University Graduate School of Design provided very helpful assistance with the illustrations. The CP Group for the funding for the underlying research through the Health and Places Initiative project at the Harvard University Graduate School of Design. 


\section{References}

Alexander, C. 1965. "A City Is Not a Tree," Architectural Forum 122(1): 58-62

American Planning Association. 2016. "Characteristics and Guidelines of Great Streets." https://www.planning.org/greatplaces/streets/characteristics.htm

Bater, J.H. 1980. The Soviet City: Ideal and Reality. Beverly Hills, CA: Sage Publications.

Bausells, M. 2016. "Superblocks to the rescue: Barcelona's plan to give streets back to residents." The Guardian. May 17.

https://www.theguardian.com/cities/2016/may/17/superblocks-rescue-barcelona-spainplan-give-streets-back-residents

Bray, D. 2005. Social Space and Governance in Urban China: The Danwei System from Origins to Reform. Stanford: Stanford University Press.

Brower, S. 1996. Good Neighborhoods: A Study of in-town and Suburban Residential Environments. Westport, CT: Praeger.

Carmona, M., T. Heath, T. Oc, S. Tiesdell. 2010. Public Places, Urban Spaces: The Dimensions of Urban Design. London: Routledge.

Chan, C. L.W. 1993. The Myth of Neighbourhood Mutual Help: The Contemporary Chinese Community-Based Welfare System in Guangzhou. Hong Kong: Hong Kong University Press.

Communist Party of China Central Committee. 2016. "State Council Issues Some Guidelines to Further Reinforce the Management of Urban Planning and Construction [Zhonggong Zhongyang Guowuyuan Guanyu Jinyibu Jiaqiang Chengshi Guihua Jianshe Guanli Gongzuo De Ruogan Yijian].” Xinhua News Agency. February 6. http://news.xinhuanet.com/politics/2016-02/21/c_1118109546.htm

Derleth, J. and D. R. Koldyk. 2004. "The Shequ Experiment: Grassroots Political Reform in Urban China." Journal of Contemporary China 13(41): 747-777.

Dong, J., T. Cheng, J. Xu, and J. Wu. 2013. "Quantitative Assessment of Urban Road Network Planning Hierarchy," Town Planning Review 84(4): 445-472.

Dray-Novey, A. 1993. "Spatial Order and Police in Imperial Beijing," The Journal of Asian Studies 52(4): 885-922.

French, R.A. and F.E.I. Hamilton, eds. 1979. The Socialist City: Spatial Structure and Urban Policy. Chichester, N.Y.: Wiley.

Gao, X. and N. Zhang. 2006. "Advantages and Disadvantages of Enclosed Residential Neighborhoods and Their Possible Solutions [Fengbishi Xiaoqu De Libi Ji Qi Duice]." Shanxi Architecture [Shanxi Jianzhu] 19: 34-35.

Gayah, G. and C.F. Daganzo. 2012. "Analytical Capacity Comparison of One-Way and TwoWay Signalized Street Networks," Transportation Research Record Journal of the Transportation Research Board 2301(1): 76-85.

Gilderbloom J. and W. Riggs. 2015. "Two-Ways to Fix Our Downtown Neighborhoods". http://sun.louisville.edu/pdfs/love\%20is\%20a\%20two-way\%20street.pdf

Grammenos, F., B. Craig, D. Pollard, and C. Guerrera. 2008. "Hippodamus Rides to Radburn: A New Model for the $21^{\text {st }}$ Century." Journal of Urban Design 13(2): 163-176.

Guangzhou Daily. February 23, 2016. "How Difficult Will It Be to Open Enclosed Neighborhoods? There Ought To Be A Transitory Phase [Fengbi Xiaoqu Kaifang Shixing Nandu You Duo Da? Ying You Guoduqi].” Guangzhou Daily http://house.21cn.com/news/a/2016/0223/08/30653698.shtml 
Han, J. and Y.B. Wang. February 23, 2016. “Opening Neighborhoods Isn't Simply A Case of "Tearing Down Walls and Opening Compounds", Complementary Suite of Policies and Amenities Also Needed [Kaifang Xiaoqu Bu Jin Shi "Chai Qiang Po Yuan”, Xu Peitao]." Xinhua News. http://www.planning.org.cn/news/view?id=3679

Harvard University Graduate School of Design Health and Places Initiative. 2016. "Research on Chinese Neighborhoods and Health, (2013 to 2016)."

http://research.gsd.harvard.edu/hapi/research/chinese-neighborhoods-and-health/

Huang, H. February 22, 2016. "A Batch of Unique, Innovative Smart Cities to be built by 2020 [2020 Nian Jiang Jiancheng Yipi Tese Xianming De Zhihui Chengshi]," Xinhua News Agency. http://news.xinhuanet.com/info/2016-02/22/c_135119029.htm

Jacobs, A.B. 1993. Great Streets. Cambridge, M.A.: MIT Press.

Jacobs, J. 1961. The Death and Life of Great American Cities. New York: Random House. 2002 reprint.

Jia, X. and X. Wang. December 15, 2001. "Hujiayuan Creates a New Modern Community [Hujiayuan Dazao Xiandaihua Xinshequ]", Beijing Daily.

Kong X.Q. February 26, 2016. "Beijing's Administrative Sub-Center To Have Pilot Projects That Will Break Down Walls and Open Roads [Po Qiang Tong Lu Ni Zai Beijing Xingzheng Fuzhongxin Shidian].” Xinhua News http://forum.xinhuanet.com/thread/138851185/1.html

Lan, L. December 25, 2012. "Concerns Rise Over Local Governments' Increased Debt Burden.” China Daily http://www.chinadaily.com.cn/bizchina/2012-12/25/content_16050284.htm

Li, B. and P.X. He. 2015. "Research on the Existing Enclosed Nature of China's Residential Districts and Explorations of Their Openness [Wo Guo Juzhuqu Xianzhuang Fengbixing Yanjiu Ji Kaifangxing Tanxi]." Frontiers of Engineering Management [Gongcheng Guanli Qianyan] http://www.chinaqking.com/yc/2015/481006.html

Li, J. February 23, 2016. "Supreme Court Discusses the "Opening of Neighborhoods": Will Pay Close Attention to Protecting the Rights of Owners [Zuigaofa Tan "Xiaoqu Kaifang": Jiang Miqie Guanzhu Yezhu Quanyi Baozhang]." People Net [in Chinese] http://legal.people.com.cn/n1/2016/0223/c42510-28143325.html

Li, W. 2013. "Developing Multi-Dimensional Framework for Evaluating the Sustainability of Residential Sub-Districts in Urban China." Ph.D. diss., University of New South Wales.

Liu, B., B. Yan, H. Zhang, Z.Wang, and Y.He. May 24, 2016. "An Exploration Regarding the Reconstitution of the Urban Road Hierarchy System [Guanyu Chonggou Chengshi Daolu Fenlei Tixi De Tantao]," Transportation Online [in Chinese]. http://www.jt12345.com/article-23706-1.html

Love, T. 2009. "Urban Design After Battery Park City: Opportunities for Variety and Vitality." In Urban Design, edited by A. Krieger and W.S. Saunders, 208-226. Minneapolis: University of Minnesota Press.

Lu, D. 2006. "Traveling Urban Form: The Neighborhood Unit in China." Planning Perspectives 21(4): 369-392.

Luo, A., Z. Wang, J. Wang, S. Rashid, and P. Calthorpe. 2011. "New Urban Roadway Form in China: A Case Study for Kunming." Seventh Advanced Forum on Transportation of China DOI: $10.1049 / \mathrm{cp} .2011 .1368$

Lü, J., P.G. Rowe, and J. Zhang, eds. 2001. Modern Urban Housing in China: 1840 to 2000. New York: Prestel.

Mah, D. and L.A. Villoria, eds. 2016. Lifestyled: Health and Places. Berlin: Jovis. 
Marshall, S. 2005. Streets and Patterns. London: Spon Press.

Marshall, W.E. and N.W. Garrick. 2011. "Evidence on Why Bike-Friendly Cities are Safer for All Road Users," Environmental Practice 13(1): 16-27.

Miao, P. 2003. "Deserted Streets in a Jammed Town: The Gated Community in Chinese Cities and Its Solution." Journal of Urban Design 8(1): 45-66.

Ministry of Housing and Urban-Rural Development of the People's Republic of China. February 22, 2016. Excerpts from "State Council Issues 'Key Directives' to Further Reinforce the Management of Urban Planning and Construction [Zhonggong Zhongyang Guowuyuan Guanyu Jinyibu Jiaqiang Chengshi Guihua Jianshe Guanli Gongzuo De Ruogan Yijian].” http://www.mohurd.gov.cn/zxydt/201602/t20160222_226694.html

National People's Congress. 2004. "Constitution of the People's Republic of China." http://www.npc.gov.cn/englishnpc/Constitution/2007-11/15/content_1372963.htm

National People's Congress. 2009. "Property Law of the People's Republic of China." http://www.npc.gov.cn/englishnpc/Law/2009-02/20/content_1471118.htm

Nguyen, T. 2013. "Governing through Shequ/Community: The Shanghai Example." International Journal of China Studies 4(2): 213-231.

Ni, G. July 29, 2000. "Defensible Residential Villages [Shefang De Xincun]”, Xin Jinshan News.

Perry, C. 1929. "The Neighborhood Unit." In Neighborhood and Community Planning Regional Survey, Volume VII. New York: Regional Plan of New York and its Environs.

Pope, A. 1996. Ladders. Princeton, N.J.: Princeton Architectural Press.

Plunz, R. and M. Sheridan. 2006. "Deadlock Plus 50: On Public Housing in New York." In Urban Planning Today: A Harvard Design Magazine Reader, edited by W. S. Saunders. University of Minnesota Press, pp.14-23

Read, B. L. 2000. "Revitalizing the State's Urban 'Nerve Tips'." The China Quarterly 163: 806220.

Read, B. L. 2008. "Assessing Variation in Civil Society Organizations: China's Homeowner Associations in Comparative Perspective." Comparative Political Studies 41(9): 12401265.

Read, B.L. with R. Pekkanen, eds. 2009. Local Organizations and Urban Governance in East and Southeast Asia: Straddling State and Society. London: Routledge.

Rowe, P.G., A. Forsyth, and H.Y. Kan. 2016. China's Urban Communities: Concepts, Contexts, and Well-being. Basel: Birkhäuser.

Rowe, P.G. and H.Y. Kan. 2014. Urban Intensities: Contemporary Housing Types and Territories. Basel: Birkhäuser.

Rowe, P.G. 2011. "Urban Residential District Making." In The People's Republic of China at 60: An International Assessment, edited by W. C. Kirby. Cambridge, Mass.: Harvard University Asia Center, 169-171.

Shougang (Capital Steel) Group. 2014. "New Shougang: High-end Industrial Mixed-Use Services District [Xin Shougang Gaoduan Chanye Zonghe Fuwu Qu]". http://www.shougang.com.cn/shougang_cn_web/yqgknr/19937.htm\#sjtcydw

Silver, C. 1985. "Neighborhood planning in Historical Perspective." Journal of the American Planning Association 51: 161-174.

Sun, N. 2007. "Scale and Borders: A Reflection on the Enclosed Neighborhoods on the Periphery of Chinese Cities [Chidu Yu Bianjie: Fansi Zhongguo Chengshi Bianyuan Fengbishi Zhuzhaiqu]." Beijing Planning Review [Beijing Guihua Jianshe Zhazhi] 1: 136-141. 
Tao, F. and F. Chu. February 23, 2016. "How Foreign Urban Block Structures Were Formed [Guowai Jiequzhi Shi Ruhe Liancheng De]," Beijing Business Today. http://finance.sina.com.cn/roll/2016-02-23/doc-ifxprqea5020135.shtml

U.S. Department of Transportation Federal Highway Administration. May 24, 2016. "Road Design: One-Way/Two-Way Street Conversions". http://safety.fhwa.dot.gov/saferjourney1/library/countermeasures/13.htm

Wang, S. 1962. "Discussion of the Layout of Residential District-Level Commercial Facilities [Juzhuquji Shangye Fuwu Sheshi Shezhi Xingshi De Tantao]," Architectural Journal [Jianzhu Xuebao] 4: 20-26.

Ward, S. V. 2002. Planning the Twentieth-Century City: The Advanced Capitalist World. Chichester: John Wiley \& Sons.

Webster, C., G. Glasze, and K. Frantz. 2002. "The Global Spread of Gated Communities." Environment and Planning B 29: 315-320.

Wei, L. L. 2016. "China to Shift Debt Burden in Tax Overhaul.” The Wall Street Journal March 7. http://www.wsj.com/articles/china-to-revise-tax-regulations-1457358027

Wei, W. and L.F. Qin. 2011. "Understanding the Enclosed Residential Districts in Chinese Cities [Dui Zhongguo Chengshi Fengbi Zhuqu De Jiedu].” Architectural Journal [Jianzhu Xuebao] 2: 5-8.

Whiting, S. 2004. “Chicago - Superblockism: Chicago's Elastic Grid.” In Histories of Cities: Design and Context, edited by R. el-Khoury and E. Robbins. London: Spon/Routledge, 57-76.

Wong, V. 2014. "Land Policy Reform in China: Dealing with Forced Expropriation and the Dual Land Tenure System." The University of Hong Kong Faculty of Law Occasional Paper No. 25. https://www.law.hku.hk/ccpl/pub/OP\%20No\%2025\%20Vince\%20Wong.pdf

The World Bank and the Development Research Center of the State Council, the People's Republic of China. 2014. Urban China: Toward Efficient, Inclusive, and Sustainable Urbanization. https://www.worldbank.org/content/dam/Worldbank/document/EAP/China/WEB-UrbanChina.pdf

Wu, W. April 1, 2016. "Vice-Minister of Housing and Urban-Rural Development: To Open Enclosed Neighborhoods is to Open the Gates and Not Demolish the Walls [Zhujianbu Fubuzhang: Dakai Fengbi Xiaoqu Shi Kai Men Bu Shi Chai Qiang],” The Beijing News. http://news.sina.com.cn/c/2016-04-01/doc-ifxqxqmf3837254.shtml

Wu, X. January, 2016. “China's Growing Local Government Debt Levels.” MIT Center for Finance and Policy Brief. http://gcfp.mit.edu/wp-content/uploads/2013/08/China-LocalGovt-Debt-CFP-policy-brief-final.pdf

Xinhua News, February 21, 2016. "China Outlines the 'Blueprint' for Future Urban Developments [Zhongguo Gouhua Weilai Chengshi Fazhan 'Luxiantu'].” http://news.xinhuanet.com/politics/2016-02/21/c_1118109733.htm

Xinhua News, February 23, 2016. "From Enclosed to Open, This Isn't Just an Urban Blueprint for the Future [Cong Fengbi Dao Kaifang, Zhe Bu Jin Shi Yi Zhang Weilai Chengshi Luxiantu].” http://www.zj.xinhuanet.com/kfkt/2016-02/23/c_1118125705.htm

Xiu, J. February 25, 2016. “Origins of China's Enclosed Neighborhoods [Zhongguo Fengbi Xiaoqu De Youlai]," China News. http://fangtan.china.com.cn/2016$\underline{\text { 02/25/content_37871485.htm }}$ 
Zhang, Y., X. Li, A. Wang, T. Bao, and S. Tian. 2015. "Density and Diversity of OpenStreetMap Road Networks in China," Journal of Urban Management 4 (2015): 135146. 